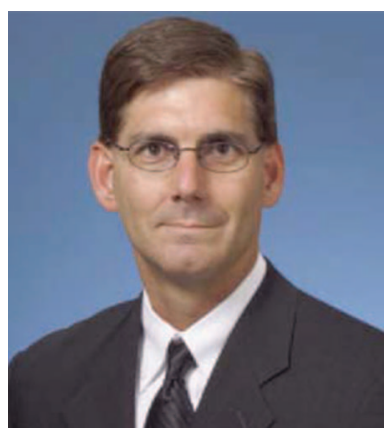

\title{
Student Manuscript Fast-Track Review?
}

The Student Advisory Board of Optical Engineering is comprised of students from universities that perform graduatelevel research in the area of optical engineering. Current student board members are from the University of Arizona, University of Central Florida, University of Delaware, Georgia Tech, University of Memphis, and the University of Rochester. The Student Advisory Board has been run by Associate Editor Dr. Eddie Jacobs, who is also the current Electrical Engineering Department Chair at the University of Memphis.

Dr. Jacobs and I have requested input and suggestions from the student board members that will make Optical Engineering a better journal. Especially desirable are those suggestions that can help the journal when our outstanding graduate students become the next practicing faculty, lab scientists and engineers, and industry executives. Very valuable input has been provided by the students in the way of improving search engine optimization for Optical Engineering, improving e-alert messages in technical research areas, and delivery media for the journal in the future.

One particular suggestion that the students provided this year was to have a "fast track review" for students that rely on a journal publication to graduate. That is, when they finish their thesis or dissertation, they would like a speedy method for having their paper reviewed. In some cases, the student's graduation depends on whether this work is publishable by a journal. This request is similar to frequent e-mails I receive from graduate students requesting that I provide a rapid evaluation of their manuscript since their graduation will be delayed until the manuscript is accepted for publication.

Being a "service-oriented" editor for the electro-optical community, I brought this suggestion up at the SPIE Board of Editors meeting, the SPIE Publications Committee meeting, and the Optical Engineering Board of Editors meeting. I was very surprised at the negative reception that the idea received. Most of the reluctance to pursue the idea was provided by faculty members on the above boards. However, after hearing the counter arguments, I understood their reluctance. Most of the faculty members mentor their students to write the journal paper first and then the thesis or dissertation. Many of the faculty members felt that the students' "rush" to publish was a result of a poor work ethic and planning on the part of the student. Finally, all of the faculty members felt that students need to learn how professional journals conduct business, and that they need to go through the standard course of competitive review (without any special consideration) since they will need to compete in this environment in the future. In fact, a few faculty members felt that making a special track for graduate student work would dilute the importance of a published journal paper.

On these points, I think that the faculty members had strong arguments. Initially, my primary concern was having different acceptance rates for the primary track and the graduate student track. A bigger concern was having two different times to get through the review process (i.e., time to decision). A question I would have to ask is "why can't both tracks be more rapid?" So, we are not going to pursue a graduate work review track at this time. However, I do want to say that the input provided by the Student Advisory Board has been extremely valuable and very worthwhile in a way that has made a difference for Optical Engineering. The only reason I brought this particular item up in an editorial is that I thought the two very different points of view were interesting. Students, keep up the good work!

On a final note, Dr. Jacobs has given me notice that he is no longer able to mentor the Student Advisory Board due to increased commitments. He has been a fantastic mentor, and I want him to know that I really appreciate his dedicated efforts for Optical Engineering.

Ronald G. Driggers Editor 